\title{
Equine viral vaccines: the past, present and future
}

\author{
Jules Maarten MiNKE ${ }^{\mathrm{a} *}$, Jean-Christophe AUDONNET $^{\mathrm{b}}$, Laurent FISCHER $^{\mathrm{c}}$ \\ a Department of Project Management, Merial SAS, Bâtiment 35 G, 254 rue Marcel Mérieux, \\ 69007 Lyon, France \\ b Department of Molecular Biology, Merial SAS, Bâtiment 38.4, 254 rue Marcel Mérieux, \\ 69007 Lyon, France \\ c Department of Gene Therapy, Merial SAS, Bâtiment 38.4, 254 rue Marcel Mérieux, \\ 69007 Lyon, France
}

(Received 4 August 2003; accepted 13 January 2004)

\begin{abstract}
The increasing international movement of horses combined with the relaxation of veterinary regulations has resulted in an increased incidence of equine infectious diseases. Vaccination, along with management measures, has become the primary method for the effective control of these diseases. Traditionally modified live and inactivated vaccines have been used and these vaccines have proven to be very successful in preventing disease. However, there are a number of equine infectious diseases for which conventional technology has shown its limitations. The advent of recombinant technology has stimulated the development of second generation vaccines, including gene deleted mutants, live vectored vaccines and DNA vaccines. These vaccines have in common that protective antigens are endogenously processed and presented along the molecules of the MHC I and MHC II complex, resulting in the stimulation of both humoral and cell-mediated immune responses similar to natural infection. The present paper provides a review of the vaccines being employed today against the most important equine viral diseases followed by a summary of new developments that are expected to bring improved vaccines to the market in the foreseeable future.
\end{abstract}

horse / viral diseases / vaccinology / novel strategies

\section{Table of contents}

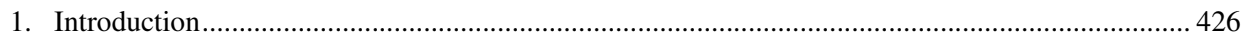

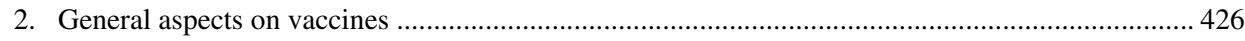

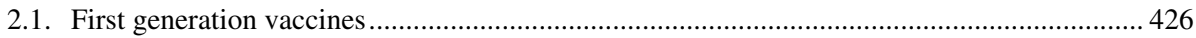

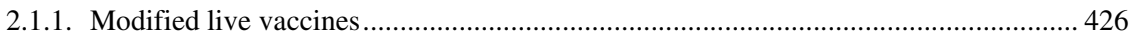

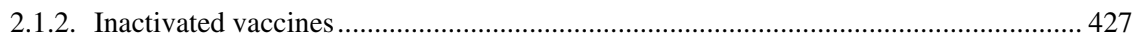

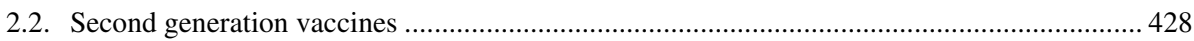

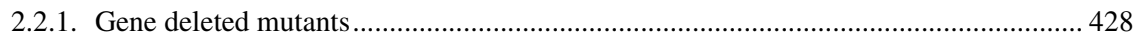

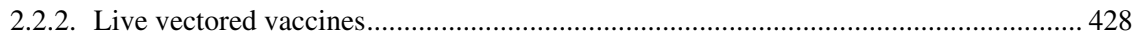

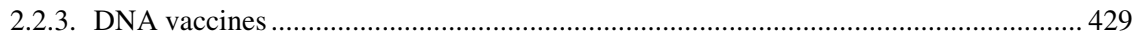

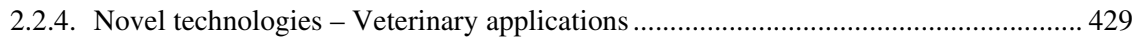

3. Vaccines against the most important viral diseases ............................................................... 430

\footnotetext{
* Corresponding author: julius.minke@merial.com
} 


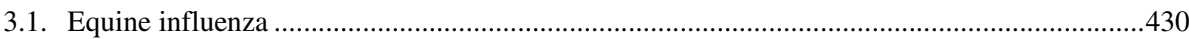

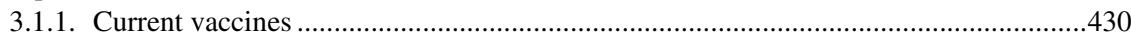

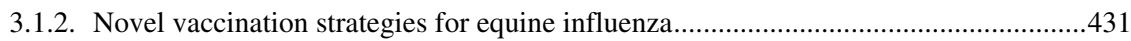

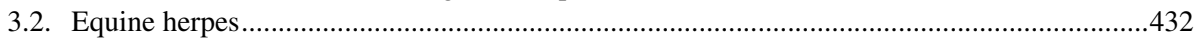

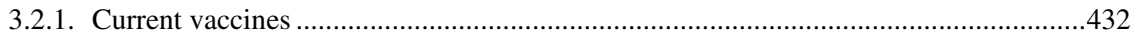

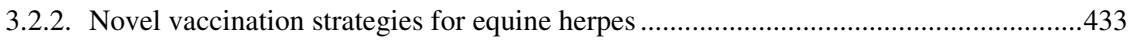

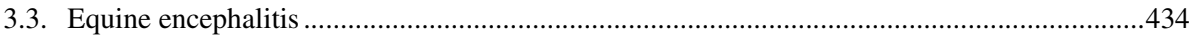

3.3.1. Current vaccines ............................................................................................

3.3.2. Novel vaccination strategies for equine encephalitis ..................................................435

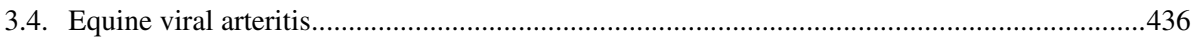

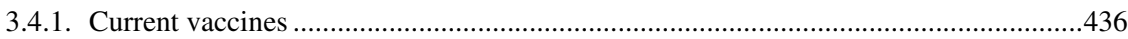

3.4.2. Novel vaccination strategies for equine viral arteritis ....................................................436

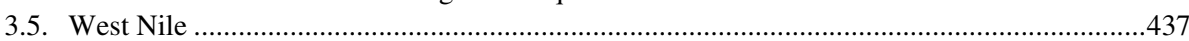

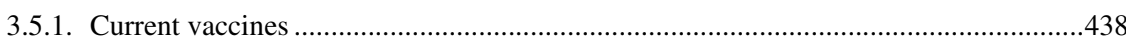

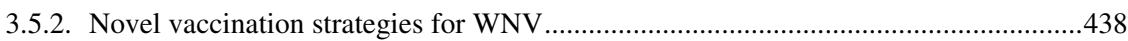

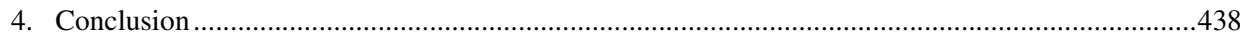

\section{INTRODUCTION}

The development of veterinary vaccines has been one of the most important contributions to the health and welfare of domestic animals. Vaccination, along with management measures, remains the most cost effective method to reduce animal suffering and economic losses from infectious diseases, and the control of diseases of veterinary importance such as pseudorabies and rinderpest through vaccination are well recognised. In addition, vaccination has helped to reduce the transmission to man of organisms with zoonotic potential such as rabies and Venezuelan encephalitis.

The increasing international movement of horses combined with the relaxation of veterinary regulations has resulted in an increased incidence of equine infectious diseases, and vaccination has become the primary method for the effective control of these diseases (reviewed in [80]).

The present paper provides a review of existing vaccines against the most important equine viral diseases followed by a summary of the new developments that are expected to bring improved equine vaccines to the market in the foreseeable future.

\section{GENERAL ASPECTS ON VACCINES}

\subsection{First generation vaccines}

The existing vaccines can be divided into modified live and inactivated vaccines.

\subsubsection{Modified live vaccines}

Modified live vaccines were amongst the first vaccines available for horses. They consist of attenuated micro organisms that replicate in vivo, thereby eliciting an immune response similar to that induced by natural infection. Attenuation usually is obtained by:

- in vitro passages through one or more cell types,

- selection of spontaneous or induced temperature sensitive mutants,

- use of re-assortants obtained by co-infection of the same cell with two different viruses with segmented genomes.

In general, modified live vaccines induce a rapid onset of immunity which is both broad and long lasting. Solid immunity is often obtained after a single dose. Notwithstanding their efficacy profile, live vaccines 
Table I. Commercially available vaccines for the equine industry.

\begin{tabular}{|c|c|c|c|c|}
\hline \multirow{2}{*}{ Disease } & \multicolumn{2}{|c|}{ Conventional vaccines } & \multirow{2}{*}{$\begin{array}{l}\text { Second generation } \\
\text { vaccines }\end{array}$} & \multirow{2}{*}{ Literature reference } \\
\hline & Inactivated & Modified live & & \\
\hline Influenza & $x$ & $x$ & $x$ & {$[18,48,59,61,67,68,92]$} \\
\hline \multicolumn{5}{|l|}{ Equine herpes } \\
\hline$-\mathrm{EHV}-1$ & $x$ & $x$ & & {$[1,11-14,44,55]$} \\
\hline- EHV-4 & $x$ & & & {$[40,41,60]$} \\
\hline Equine viral arteritis & $x$ & $x$ & & {$[33,56,58,91,100]$} \\
\hline \multicolumn{5}{|l|}{ Equine encephalitis } \\
\hline - Western & $x$ & & & \\
\hline - Eastern & $x$ & & & {$[32]$} \\
\hline - Venezuelan & $x$ & $x$ & & {$[7,26,27,47,52,97,98]$} \\
\hline West Nile & $x$ & & $x$ & {$[62]$} \\
\hline African Horse Sickness & $x$ & $x$ & & \\
\hline Rabies & $x$ & & & \\
\hline Rota & & $x$ & & \\
\hline Strangles & $x$ & $x$ & & \\
\hline Tetanus & $x$ & & & \\
\hline Clostridium perfringens & $x$ & & & \\
\hline $\begin{array}{l}\text { Equine protozoal } \\
\text { myeloencephalitis (EPM) }\end{array}$ & $x$ & & & \\
\hline Potomac horse fever & $x$ & & & \\
\hline Equine infectious anemia & & $x^{a}$ & & \\
\hline Japanese encephalitis & $x$ & & & \\
\hline
\end{tabular}

a Only available in China.

continue to be viewed with caution in certain countries. Concerns include a possible reversion to virulence sometimes leading to fatal disease in vaccinated animals and a lack of safety in pregnant or immuno-compromised animals. There are several modified live vaccines currently on the market for horses, including, but not limited to, vaccines for equine herpes, equine influenza, equine encephalitis, and equine viral arteritis (Tab. I).

\subsubsection{Inactivated vaccines}

Inactivated vaccines comprise microorganisms which are heat or chemically inactivated. Formaldehyde, $\beta$-propriolactone, ethylene-imine and thimerosal are among the most frequently used inactivating agents. Subunit vaccines constitute a special category of inactivated vaccines. Extraction and purification of immunogens from viruses or bacteria are used to formulate these vaccines. In order to develop subunit vaccines, it is essential to identify the (immunogenic) fractions that are important for the induction of the immune response. After extraction and purification, the antigens are usually mixed with an adjuvant to stimulate the immune system. Vaccines against tetanus containing tetanus toxoid or vaccines against strangles based on the $\mathrm{M}$ protein are the best known examples of veterinary subunit vaccines. Inactivated vaccines are inherently biologically safe since they have, in theory, no residual virulence, but in order to be efficacious they often need high antigenic mass and strong adjuvants. There are several disadvantages commonly associated with inactivated vaccines such as the slow onset of immunity, local reactogenicity and residue, the need for multiple injections in order to 
be effective, the risk of incomplete inactivation and hazards to personnel and the immediate environment when working with large amounts of potentially zoonotic pathogens. Furthermore, since inactivated vaccines are known to be weak inducers of cell-mediated immunity, they are not very efficient in eliminating virus infected cells. A wide variety of inactivated and subunit vaccines are commercially available for horses (Tab. I).

\subsection{Second generation vaccines}

Conventional vaccines have proven to be very successful in preventing disease. However, there is a concerted effort to define safer and more effective vaccines that would overcome the disadvantages of current preparations. Also, new vaccines are sought to protect against emerging diseases for which no prophylaxis is currently available. The advent of recombinant DNA technology has stimulated the development of second generation vaccines, including but not restricted to gene deleted mutants, attenuated live vectors and DNA vaccines. All these vaccines have in common that the protective antigens are endogenously processed and presented along with the major histocompatibility complex (MHC) class I and II molecules, resulting in the stimulation of both humoral and cell-mediated immune responses in a manner similar to natural infection. Cytotoxic T lymphocytes (CTL) are particularly important in the clearance of virus infected cells and the control of cell-associated viremia. In order to use recombinant technology, it is essential to identify those proteins containing CTL epitopes. As was shown for equine infectious anemia virus [57] and equine herpesvirus 1 [87], CTL responses in the horse are MHC class I (or ELA-A in the horse) restricted. The latter molecules are highly polymorphic, meaning that epitopes inducing strong CTL responses in horses expressing one MHC allele might not be immunogenic in horses expressing a different allele. The identification of broadly recognised, dominant epitopes that induce strong CTL responses in horses with different genetic backgrounds is a major challenge and the subject of future research [57, 87]. However, it is realistic to assume that a single protein most probably will not fulfil this requirement.

\subsubsection{Gene deleted mutants}

Specific modifications or deletions can be introduced in the genome of microorganisms so that they become stably attenuated through the use of recombinant technology. The availability of full-length cDNA clones for example for equine Venezuelan encephalitis virus [22] and equine arteritis virus [37] has greatly facilitated the directed introduction of specific mutations in the genome and the development of gene-deleted live vaccines. Genetically engineered vaccines have also provided the basis for the development of Differentiating Infected from Vaccinated Animals (DIVA) vaccines by the introduction of deletions in non-essential genes encoding for immunogenic proteins.

\subsubsection{Live vectored vaccines}

Viruses or bacteria can be genetically engineered to serve as carriers or vectors for the expression of foreign DNA through the use of recombinant technology. Live recombinant vectors will present the transgene in the context of an infection and therefore stimulate both B and T cell responses. Adenoviruses and herpes viruses are being considered and evaluated as potential vaccine vectors, whereas a variety of recombinant poxviruses, based on either vaccinia or avipox viruses are already commercially available. Several features of poxviruses, including their capacity to insert large segments of foreign DNA and their thermo- and genetic stability, make them ideal candidate vectors for delivering foreign antigens from a wide variety of pathogens to the host immune system. In contrast to the vaccinia virus, which has a very broad vertebrate host range, 
the canary and fowlpox viruses are host restricted to certain avian species and produce an abortive infection in mammal. Canarypox virus recombinants have been shown to authentically express the inserted foreign genes in the absence of productive viral replication [78], which provides a built-in safety feature for vaccination, since there is no potential for transmission of the vaccine vector. Further advantages are related to the fact that there is no neutralising immunity against the vector that precludes an immune response against the transgene after subsequent administrations, and their ability to deliver immunity in the absence of an adjuvant. Several canarypox recombinant vaccines have been developed for veterinary use and are now commercially available in North America and Europe [62, $75,79,88]$.

\subsubsection{DNA vaccines}

Since the pioneering work of the early 1990s, vaccination with plasmid DNA has proven to be a valid alternative to conventional vaccines, both for human and veterinarian use. The basis for DNA immunisation is that cells can take up "naked" DNA and that foreign genes can be expressed within in vivo transfected cells. Genes coding for immunogens of pathogens can be incorporated into plasmids under the control of eukaryotic promoters in order to get expression when administered in vivo. Plasmid based vaccines offer many of the potential benefits of live vaccines without the same inherent risks, such as reversion to virulence. The most compelling feature of DNA vaccination is related to safety, because they can be manufactured in the absence of substances of animal origin and can be highly purified. Further advantages are related to the de novo synthesis of antigens structurally identical to those produced during an active infection resulting in the stimulation of both humoral and cellular immune responses [83] and to their ability to overcome maternal derived immunity in neonates or in very young animals [28]. However, a disadvantage of DNA vaccines is that they trigger relatively weak serological responses against certain antigens when compared to conventional vaccines. Various attempts to improve the potency of plasmid DNA-based vaccines have produced encouraging results in animal models. They involve the co-expression of the antigen along with cytokines, the targeting of the recombinant antigen to specific cells of the immune system, the administration of the plasmid through needle less devices, the formulation of plasmids with adjuvants like aluminium phosphate or monophosporyl lipid A and the complexation of DNA with cationic lipids. Our laboratory recently demonstrated [29] that a rabies DNA plasmid formulated in the cationic lipid DMRIE-DOPE triggers significantly enhanced neutralising antibody titres against rabies in the horse as compared to naked DNA. These results confirm former data indicating that DNA vaccination could be effective in the horse [53] and clearly indicate that properly formulated DNA vaccines can generate immune responses in the horse that are at least equivalent to those achieved with conventional vaccines. Hypothetical safety concerns, including the potential integration of plasmid DNA into the genome or the generation of anti-DNA antibodies that could lead to auto-immune disease have been addressed by several laboratories and have been determined to be of remote risk.

\subsubsection{Novel technologies - Veterinary applications}

There are a number of equine infectious diseases for which conventional vaccine technology has shown its limitations. The development of improved respiratory vaccines generating an adequate and sustained immune response even when natural immunity fails to do so has been identified as a key area of interest. There is definitely a need for safe and efficacious vaccines for the prevention of equine herpes virus abortion and myeloencephalitis and real concerns about the safety and efficacy of current equine encephalitis vaccines will fuel further research on improved vaccines. 
Other aspects of currently available vaccines perceived as limitations are a lack of efficacy in the face of maternally derived immunity and the inability to differentiate naturally infected animals from vaccinated animals (DIVA).

A DIVA vaccine (also termed marker vaccine) can be a subunit, gene-deleted, vector or DNA vaccine and is always used in conjunction with a diagnostic test. The basis of this technology is that vaccinated animals do not induce antibodies to a marker protein that is absent from the vaccine, but included in a diagnostic test. These vaccines can be used to eradicate viral infections or control the spread of exotic diseases in a country. DIVA vaccines have been successfully used in eradication schemes for pseudorabies in swine and infectious bovine rhinotracheitis in cattle in some European countries (reviewed in [95]). No application is known for equine vaccines yet, but some of the advantages of DIVA vaccines also do apply to equine vaccines and are being explored to develop new vaccines against equine arteritis virus (see Sect. 3.4.2).

Recombinant technology potentially offers solutions to these issues and holds the key to the development of vaccines with the immunogenic advantages of live vaccines combined with the safety profile of killed vaccines.

The past, current and future of equine vaccinology will be described in more detail on the basis of the most important equine viral diseases, i.e. equine influenza, equine herpes, equine viral arteritis, equine encephalitis and West Nile.

\section{VACCINES AGAINST THE MOST IMPORTANT VIRAL DISEASES}

\subsection{Equine influenza}

Equine influenza is generally recognised as an important disease of horses and results from infection with H7N7 or H3N8 influ- enza A viruses. The H7N7 viruses have not been isolated since 1980 and may be extinct [99], whereas influenza H3N8 viruses continue to cause outbreaks and important economic losses to the horse industry [64]. The prevention and control of equine influenza largely depends on vaccination and the application of management regimes. Multiple factors can influence vaccine efficacy including the strain composition, antigenic content, adjuvant and timing of administration. The influenza H3N8 virus is highly prone to small changes (antigenic drift). The ability of the virus to undergo these constant antigenic changes makes it necessary to periodically update the vaccine strains to reflect the latest epidemiological situation [102]. Apart from vaccine potency (see below) and strain composition, the timing of vaccination is important and can have an impact on vaccine efficacy. It is well accepted that even low levels of maternal antibodies can interfere with successful immunisation $[20,94,96]$ and determine the proper time of vaccination. The disappearance of these antibodies can be monitored by Haemagglutination Inhibition (HI), Single Radial Haemolyis (SRH) or Enzyme Linked Immunosorbant Assays (ELISA) and the results of several independent studies $[20,94,96]$ have shown that the majority of foals born to vaccinated mares should not be vaccinated before 24 weeks of age. There is a point of controversy with some authors claiming that vaccination in the face of residual maternal antibodies is contra-indicated and results in non-responsiveness to subsequent vaccine doses [20]. Also the timing of re-vaccination is important since vaccinating too frequently or boosting too early is associated with poor immune responses (Townsend H., personal communication).

\subsubsection{Current vaccines}

Historically, equine influenza virus (EIV) vaccines contain inactivated whole virus or surface antigens (split vaccines) for parental administration and have been available since the early nineteen-sixties [9]. The 
antigens are produced either on eggs or tissue culture and are mixed with a suitable adjuvant to improve immunogenicity. The vaccines are commercialised either as monovalent vaccines or in combination with tetanus toxoid, equine herpesvirus and/or encephalitis antigens. The protection provided by conventional inactivated vaccines is dependent upon the concentration of circulating antibodies to the haemagglutinin surface glycoprotein [65]. It is generally accepted that these antibodies are shortlived, requiring revaccination at 3-4-monthintervals to maintain immunity in populations at high risk. A clear correlation has been established between the HA content of killed vaccines (measured by the Single Radial Diffusion assay), the levels of SRH antibody induced in the horse and protection provided against a challenge [65]. Early inactivated EIV vaccines were licensed as a two dose regime with a recommendation for annual re-vaccination. The influenza outbreak in 1979 clearly demonstrated that the potency (immunogenicity) of these vaccines was inadequate and that these vaccines failed to stimulate high levels of antibody in the horse. Since then, EIV vaccines have been subject to continuous improvements by increasing the antigenic content (potency) and by the use of new adjuvant technologies [67, 68]. Several European vaccines now induce durable antibody responses and have a claim for a one year duration of immunity following the third dose of the vaccine $[48,67,68]$ based on data generated under experimental conditions. However, the results on field studies confirming 12-month-protection have not been published. Differences exist between inactivated EIV vaccines produced in Europe and North America. The majority of the EIV vaccines produced in North America are still the object of criticism due to real concerns about their efficacy [63] and the absence of epidemiologically relevant $\mathrm{H} 3 \mathrm{~N} 8$ strains. However a new killed vaccine that contains antigenically relevant strains of EIV H3N8 and with appropriate potency was recently licensed in the USA [59].

\subsubsection{Novel vaccination strategies for equine influenza}

In contrast to a natural influenza infection, conventional inactivated vaccines do not stimulate significant cytotoxic T-cell (CTL) responses or mucosal immunity. Cellmediated immunity is believed to play an important role in the clearance of virusinfected cells thereby reducing the length and severity of clinical disease. It has been shown that antigen-specific CTL responses persist for at least six months after experimental infection and are rapidly mobilised upon re-infection [38]. Besides the stimulation of antigen-specific CTL responses, infection with the influenza virus induces large amounts of secretory $\operatorname{IgA}$ in the respiratory tract which neutralises the infectious virus by providing a mucosal barrier to infection [69]. In view of these qualitative differences in the immune responses induced by infection and by vaccination with killed antigens, new research initiatives have been focusing on reproducing the immune responses that follow natural infection. Recently, a number of vaccines have been developed to provide a broader stimulation of the immune system.

Hannant et al. [39] showed that primed ponies vaccinated twice intra-nasally with inactivated influenza virus adjuvanted with cholera toxin B developed high levels of mucosal antigen-specific $\operatorname{IgA}$ and were clinically immune to infection and did not shed virus. To capitalize on this finding, an alternative vaccination regime was developed for a new killed influenza vaccine in the USA [59]. Following a primary course of two intra-muscular injections, the third dose was given intra-nasally six months after the second dose. Ponies vaccinated according to this schedule were protected against an infectious challenge administered six months after the third dose.

A modified live intranasal vaccine against influenza containing a cold-adapted strain of influenza A/eq/Kentucky/91 (H3N8) is now commercially available in North America. The vaccine provided partial clinical 
and virological protection against recent $\mathrm{H} 3 \mathrm{~N} 8$ influenza isolates from the USA and Europe four weeks after a single intra-nasal dose [18]. Protection lasted for at least six months after vaccination [92]. The absence of systemic humoral responses in the vaccinated ponies suggests that immune mechanisms other than serum antibody are involved in the protection.

Most recently, the first vector vaccine based on a live recombinant canarypox virus has been licensed in the European Union for use in horses. The vaccine contains two canarypox constructs expressing the HA gene of influenza A/eq/Newmarket/ 2/93 (H3N8) and A/eq/Kentucky/94 (H3N8). Early studies have shown that, although the constructs provided protection in the absence of an adjuvant, its efficacy was greatly enhanced when combined with a Carbopol adjuvant [61], with the vaccine inducing sterile immunity two weeks after vaccination. Partial protection persisted for over 10 months after the second dose as evidenced by a significant reduction in clinical scores and virus excretion after experimental infection. Protection occurred even when specific antibodies were low or absent (unpublished results), suggesting that the vaccine is generating cellular immune responses already reported for other canarypox constructs in mice [85] and humans [45]. Another possible mechanism is that vaccination properly primes the immune system allowing a rapid anamnestic antibody response ("recall") after challenge.

DNA vaccines potentially offer an alternative to classical influenza vaccines as demonstrated by Lunn et al. [53]. Ponies were "gene gun" vaccinated with three doses of plasmid DNA encoding HA from equine influenza virus administered to skin and mucosal sites. The results showed that DNA vaccination provides partial to complete protection from challenge infection in ponies. Surprisingly, protection was associated with the presence of local IgG, in the absence of $\operatorname{IgA}$ in nasal secretions. Although these results are promising and merit fur- ther research, improvements in delivery systems are necessary in order to render this technology commercially feasible and applicable for veterinary practice. In particular the site of injection and the requirement for multiple injections need attention.

\subsection{Equine herpes}

Equine herpesvirus 1 (EHV-1) and equine herpesvirus 4 (EHV-4) are the major causative agents of respiratory disease and abortions in horses, whereas EHV-1 is occasionally associated with neurological disease. Although there is controversy in the literature regarding cross protection between EHV-1 and EHV-4, with some reports claiming unilateral cross protection [30], it is now generally accepted that in order to maximise the immune responses to EHV, vaccines should contain both EHV subtypes [30]. EHV-4 is genetically stable, whereas two types (1P and 1B) have been identified for EHV-1. Allen et al. [3] reported a sudden increase of the 1B type in the early nineteen-eighties in Kentucky. Recent surveys in Europe have shown that the majority of EHV-1 isolates still belong to the $1 \mathrm{P}$ variant $[74,93]$. The impact of strain variation on vaccine performance has never been clearly established. Control programmes rely on vaccination and management practices are aimed at reducing the risk of introducing and transmitting virus in susceptible horse populations.

\subsubsection{Current vaccines}

The aim of vaccination against EHV-1 and EHV-4 is to protect horses against respiratory disease and to prevent abortion. The first vaccines contained killed EHV-1 prepared from the tissues of infected foals or hamsters [24, 25]. These vaccines were abandoned because of unacceptable local and systemic adverse reactions and poor immunogenicity. Subsequently, Doll et al. [23] developed a modified live vaccine against EHV for intranasal administration. The vaccine contains a hamster adapted 
EHV-1 virus and was used in a "planned infection" control program for immunising mares against abortion. It is recommended to use the vaccine during early stages of pregnancy since it contains some residual virulence which could cause abortion if given later during gestation. The vaccine was used until tissue culture derived vaccines, including inactivated and modified live vaccines, became available. Mayr et al. [55] developed a modified live EHV-1 vaccine derived from the $\mathrm{RacH}$ strain grown on porcine embryonic kidney cells. Detailed molecular analysis revealed that the deletion of gene 67 is responsible for its attenuation [70]. The work of Jessett et al. [44] has renewed interest in this vaccine which had been widely used for many years in Germany but for which few results from controlled challenge studies have been reported. Three doses of vaccine provide a very strong level of protection against clinical disease and almost eliminated viraemia after infection. These results are in variance with earlier reports on the efficacy of this vaccine in preventing viraemia and abortion $[11,12]$. Reports from field use suggest good safety, although the vaccine is potentially pathogenic for the equine foetus as was demonstrated after direct intra-uterine inoculation of the vaccine strain [13]. Another modified live vaccine against EHV-1 produced on VERO cells had to be withdrawn from the market after being associated with post-vaccinal myeloencephalitis [51]. Recently, a temperature-sensitive mutant of an EHV-1 strain was assessed for its ability to protect horses against respiratory infection and viraemia following experimental challenge infection [76]. Several inactivated vaccines have been tested for efficacy in equine experimental models for EHV respiratory disease and abortion. Thomson et al. [90] demonstrated that a partially purified EHV-1 virus inactivated with formaldehyde and combined with adjuvant produced good humoral responses to EHV-1, but not to EHV-4, and partially protected ponies against clinical disease and virus excretion after EHV-1 challenge. Vac- cination with an inactivated Carbomer adjuvanted EHV-1/EHV-4 vaccine partially protected ponies against clinical disease and virus excretion after an EHV-1 or EHV-4 challenge [40]. Three doses of the same vaccine significantly protected pregnant mares against EHV-1 abortion, although cellassociated viremia after challenge was not prevented [40]. Although an oil-adjuvanted killed whole virus vaccine significantly reduced the incidence of abortions in Kentucky after its launch (reviewed in [1]), this vaccine failed to protect mares against abortion in an experimental challenge model [14]. No protection could be demonstrated with an experimental EHV-1 ISCOM vaccine, in spite of high levels of serum neutralising (SN) antibody at the time of challenge [66]. Inactivated EHV vaccines, in general, do not provide long-term protection against virus challenge, although a 6-month duration of immunity against clinical disease has been demonstrated for an inactivated, Carbomer-adjuvanted vaccine $[41,60]$.

The results of these studies showed that conventional killed EHV vaccines give only partial clinical and virological protection against respiratory infections with EHV-1 or EHV-4, but do not prevent cellassociated viraemia or fully protect against abortion. The highly variable results on protection obtained in the different studies may be the result of using EHV primed animals and mares at different stages of pregnancy or may be related to breed differences.

\subsubsection{Novel vaccination strategies for equine herpes}

The ideal vaccine against EHV should protect against respiratory infections and prevent the occurrence of viremia upon infection. EHV vaccine strategies aimed only at stimulating systemic antibody responses will certainly fail to adequately stimulate the immune system [2]. Future efforts in vaccine development should include research on the stimulation of potent mucosal and cellular immune responses [2]. Recombinant 
vaccines, including gene deletion mutants, vector and DNA vaccines are expected to generate these kinds of immune responses and several experimental vaccines have been tested for protection against EHV in the horse.

A gE/gI gene deleted EHV-1 strain was found to be safe for horses, but only gave partial clinical protection against an EHV-1 challenge [54]. An experimental vaccine based on a thymidine kinase-negative $\left(\mathrm{TK}^{-}\right)$ mutant did not prevent viraemia after EHV-1 challenge [86, 89]. A canarypox EHV recombinant vaccine containing the $\mathrm{gB}, \mathrm{gC}$ and $\mathrm{gD}$ genes of EHV-1 significantly reduced virus excretion after challenge, but failed to protect against cell associated viraemia [4]. Similar results were obtained when the same, but truncated, genes were administered as a DNA vaccine to horses (unpublished results).

The results arising from these studies clearly indicate that, as for other herpes viruses, more research is needed to identify the immunodominant protective antigens of EHV and their interaction with the host immune system. Research has just started to address this issue [87]. In addition, little is known about the EHV virulence genes that could be candidates for targeted deletions in order to develop safe and efficacious vaccines. Most knowledge of the role of the different EHV proteins stems from experiments in rodent models, which are not necessarily relevant for the horse. For the time being, the real potential of vaccine candidates needs to be tested in the existing equine models, a daunting task in view of the difficulty of finding EHV seronegative and unprimed horses.

\subsection{Equine encephalitis}

Equine encephalitides are arthropod borne diseases affecting both humans and horses caused by a complex of viruses within the genus Alphavirus, family Togaviridae. Three related, but antigenically distinct viruses are recognised; western equine encephalitis
(WEE), eastern equine encephalitis (EEE) and Venezuelan encephalitis (VEE). The viruses occur only in the Americas and maintain sylvatic cycles of infection involving birds or rodents and mosquitoes. They cause sporadic epidemics with high case fatality rates in both humans and horses. Horses are considered dead-end hosts for WEE, but may serve as amplifying hosts for VEE and occasionally for EEE. EEE viruses are traditionally divided into North America and South America antigenic varieties based on haemagglutination inhibition tests. Antigenic variants of WEE, which seem to be focally distributed, have also been described [15]. The VEE viruses are classified into six subtypes (I-VI), with subtype I having six variants (IA-IF). The variants IAB and IC have been associated with epizootics in equids and humans, although recently an outbreak of encephalitis in horses was caused by an enzootic VEE strain [72]. Methods to control equine encephalitis rely on mosquito management, vaccination and movement restrictions.

\subsubsection{Current vaccines}

Live and inactivated vaccines against equine encephalitis have been developed. A modified live vaccine against VEE is available in North and South America. The vaccine strain, TC-83, is derived from the Trinidad donkey strain (variant IAB), attenuated by serial passage in guinea-pig heart cells [7]. The vaccine was originally developed for use in humans at risk for VEE virus infections. In horses, the vaccine induces long lasting neutralising antibodies [27, 98] and it was proven to be very efficacious in controlling the epidemics of VEE in Central America in the early nineteen-seventies $[26,97]$. However, several biosafety issues are associated with the use of this vaccine. The vaccine is reactogenic in horses [98] and man [77] and concerns remain about its potential to revert to virulence [52] and introduction of the strain into the mosquito population. In addition, the current VEE vaccines do not seem to fully protect against 
enzootic viruses [31], which caused two recent outbreaks among equines in Mexico [72]. There are no live vaccines available for EEE and WEE viruses.

The killed vaccines against EEE, WEE and VEE are derived from formaldehyde or ethylene-imine inactivated cell cultures. The killed vaccines are of low immunogenicity and multiple injections are required to provide adequate protection. Comprehensive studies on the duration of immunity are not available, but these vaccines are believed to provide only short-lived protection. The killed vaccines require the growth of large quantities of virus and are subject to issues including adequate biosafety in their manufacture and possible detrimental effects following incomplete virus inactivation. Some epizootic outbreaks of VEE [47] and sporadic cases of EEE [32] may have started in horses vaccinated with improperly inactivated vaccines.

\subsubsection{Novel vaccination strategies for equine encephalitis}

Real concerns about the safety and efficacy of current vaccines against encephalitis have stimulated the search for improved vaccines. In addition, since these viruses are human pathogens, there is huge interest in alternative manufacturing methods that will allow antigen production under low biocontainment conditions. Neutralising antibodies play a major role in protection and recovery from alpha virus infection, but non-neutralising antibodies as well as other effector mechanisms can be effective as well [42]. Several experimental vaccines, including recombinant vaccinia and baculovirus-vectors, chimaeric recombinants, deletion mutants and DNA vaccines have been evaluated in animal models and the horse to determine their potential as vaccine candidates.

Vaccinia VEE recombinants encoding the structural proteins (C-E3-E2-6K-E1) were evaluated for antibody induction and protection against challenge in horses [8]. Two doses of vaccine induced neutralising titres and protected horses from a lethal challenge with VEE.

The same construct induced neutralising antibodies in mice and protected mice from peripheral challenge, but not from intranasal challenge [46]. Bennett et al. [6] improved the efficacy of the vaccinia construct against a subcutaneous VEE challenge in mice by insertion of a synthetic promotor and a mutation in the E2 gene. Baculovirus expressed structural proteins of VEE were tested for immunogenicity and protection from challenge in mice [42]. The best protection was obtained by constructs expressing the entire 26S (C-E3-E2-6K-E1) or the complete envelope coding region (E3-E2-6K-E1). These constructs not only protected against disease but also against infection, with the latter correlating with the presence of neutralising antibodies. Several chimaeric constructs were tested as vaccine candidates in mice. A recombinant Sindbis/VEE virus containing the structural genes from VEE TC83 was safe for adult and suckling mice and protected mice against challenge with pathogenic strains of the VEE virus [73]. Another chimaeric construct, WEE/EEE containing the structural genes of EEE provided significant protection against an EEE challenge, but the virus had residual virulence and attempts to further attenuate the virus were unsuccessful [84]. The construction of a full-length cDNA clone of VEE has greatly facilitated the introduction of targeted mutations into the VEE genome [22]. Promising results were obtained with a double mutant of VEE (V3526) containing a deletion in the furin cleavage site and a second, independently attenuating mutation in the E2 protein [81]. The resulting virus, expressing PE2 instead of E2, was highly attenuated in mice and primates and induced protection against parenteral and aerosol challenge. The structural genes of WEE and VEE placed under the control of a human CMV immediate/ early promoter are currently being evaluated as a vehicle for DNA immunisation in mice, as a first step in the development of a DNA vaccine. 
Although promising results have been obtained in the mouse model, only one construct (vaccinia/VEE) has been tested so far for safety and efficacy in the horse. Extensive efficacy and safety testing in horses, including reversion to virulence studies, is needed to assess the potential of these constructs as vaccine candidates for horses.

\subsection{Equine viral arteritis}

Equine viral arteritis is a contagious disease of horses caused by equine arteritis virus (EAV) belonging to the Arteriviridae family. There is only one serotype of EAV, although antigenic differences exist between the virus isolates. The ability of EAV strains to produce disease can vary greatly, ranging from clinically unapparent to severe. The virus is transmitted via the respiratory and genital routes. In the majority of horses EAV infections remain sub-clinical, although mild to serious disease occurs. Chronic carrier stallions play an important role in the epidemiology of the disease since the virus is shed in the semen and transmitted to susceptible mares during mating, which can result in abortions. To minimise the spread of infection and economic losses, control programmes, including prophylactic vaccination, have been implemented in several countries.

\subsubsection{Current vaccines}

Both killed and modified live vaccines have been developed against EAV. The commercially available modified live vaccine was developed from the prototype Bucyrus strain of EAV attenuated by successive in vitro passages on equine and rabbit cells [56]. The vaccine protects against an intranasal challenge with virulent virus and provides one year of immunity against clinical disease but not against infection [91]. The vaccine is considered safe, although transient temperature responses have been observed after parenteral vaccination [33] and occasionally the virus is re-isolated from nasopharyngeal [33], rectal swabs
[33] and buffy coats [33]. Attempts to isolate the virus from semen were unsuccessful [58] and the vaccine virus does not seem to persistently infect stallions. Vaccination of pregnant mares, however, is not recommended unless they are at significant risk of natural exposure [91]. The vaccine is only available in the USA; legal obstructions and regulatory hurdles have hampered its introduction in Europe.

Fukunaga et al. [34] developed a formalin inactivated non-adjuvanted vaccine based on the Bucyrus strain of EAV propagated in tissue culture. The vaccine needs a high antigenic load to be effective and only horses with high neutralising antibody responses to the vaccine are protected against clinical disease [34], but not against infection [34]. The vaccine was successful in protecting mares against abortion [34] and stallions against persistent infection of the reproductive tract after respiratory infection. The same vaccine, but adjuvanted, protects mares from clinical disease after respiratory [35] and venereal challenge [36]. A commercially available vaccine inactivated by the use of a non-formalin agent and blended with a metabolisable adjuvant is effective at reducing clinical signs and offers protection against the establishment of persistent infection in stallions for six months (but not eight months) after two doses [100].

\subsubsection{Novel vaccination strategies for equine viral arteritis}

Due to the economic importance of the disease, movement of horses from EAV endemic to non-endemic areas is restricted. Although the current vaccines are considered safe and efficacious, the inability to discriminate vaccinated horses from infected horses is a major drawback and will interfere with surveillance programmes. The availability of a DIVA vaccine as an alternative to existing vaccines allowing the differentiation between vaccinated and naturally infected animals would simplify the international movement of horses. Several 
recombinant vaccines are being explored as potential marker vaccines for EAV.

A prototype subunit vaccine containing the entire ectodomain of the large envelope glycoprotein $\left(\mathrm{G}_{\mathrm{L}}\right)$ of EAV was assessed for protection in ponies [16]. The vaccine induced high, but short-lived SN antibody titres and multiple injections were required to maintain antibody levels. Ponies were partially protected against an intra-nasal challenge with EAV carried out 19 weeks after the fourth vaccination as judged by reduced pyrexia, viraemia and virus excretion from the nasopharynx. Protection was strongly correlated with the level of $\mathrm{SN}$ antibody at the time of challenge, but no venereal challenge was carried out. The vaccine can be used with an ELISA diagnostic test based on the $\mathrm{N}$ or $\mathrm{M}$ protein of EAV [19].

The development of a full-length infectious cDNA clone has allowed the introduction of site directed mutations into the EAV genome [37] and development of a gene deleted live vaccine. Castillo-Olivares et al. [17] developed a candidate live marker vaccine $\left(E A V-G_{L} \Delta\right)$ for $E A V$ by deletion of the major virus neutralising domain of the $G_{L}$ protein. A peptide, contained within the deleted sequence forms the basis of a discriminating ELISA assay [71]. The vaccine was well tolerated by ponies, although the vaccine virus could be easily isolated from swabs and leucocytes after intra-nasal inoculation. A single dose of vaccine provided a very high level of clinical and virological protection against oro-nasal challenge with EAV, despite weak neutralising antibody responses against the wild-type EAV strains. As expected, the combined use of the genedeleted vaccine and $\mathrm{G}_{\mathrm{L}}$-peptide ELISA assay allowed easy serological discrimination between vaccinated and infected ponies.

Alphavirus replicon particles have been extensively used as vectors to express heterologous viral genes, which are expressed in place of the alphavirus structural genes. The vector is replication defective and does not yield any progeny virus (single-hit non replicating vector). Balasuriya et al. [5] developed a recombinant Venezuelan encephalitis replicon particle (VRP) expressing the two major envelope proteins of EAV, $\mathrm{G}_{\mathrm{L}}$ and $M$. The presence of the $M$ protein was critical to the expression of neutralising epitopes on the $\mathrm{G}_{\mathrm{L}}$ protein. Two doses of EAV-VRP administered subcutaneously induced very strong neutralising antibodies to EAV and completely protected horses from intranasal challenge. However, only partial protection was provided after intrauterine challenge. The vaccine can be combined with a differential diagnostic ELISA assay based on the $\mathrm{N}$ protein of EAV.

Although promising, none of the vaccine candidates have reached the final stages of development. Neither of the constructs have been tested for protection against abortion or the establishment of persistent infection in stallions, both important criteria for EAV vaccine efficacy. The subunit vaccine and the recombinant VRP vector are non-replicating and therefore inherently safe for horses. More work needs to be carried out to evaluate the safety of the gene-deleted mutant for horses, in particular when given to pregnant mares and stallions. Although the development of DIVA vaccines for EAV has demonstrated a potential, the combined use of the vaccine and diagnostic assay will need full validation on large panels of field sera of known status.

\subsection{West Nile}

West Nile virus infection is caused by a flavivirus belonging to the Japanese encephalitis virus (JEV) sero-complex of the genus Flavivirus, family Flaviviridae. All equine isolates belong to the lineage I West Nile viruses. The virus was detected for the first time in North America in 1999 during an outbreak involving birds, horses and humans in New York City. Since then the virus has spread rapidly south and west, appearing in almost every state in the continental United States by 2002 . The primary transmission cycle of WNV involves birds and mosquitoes. Horses become infected through the 
bite of infected mosquitoes and develop a WNV viraemia of low magnitude and short duration. Therefore, infected horses are unlikely to serve as amplifying hosts for WNV and are considered incidental, deadend hosts [10]. During 2002, more than 14000 confirmed equine clinical cases of WNV infection were reported in North America, with a $30 \%$ mortality rate. There is currently no specific treatment protocol for WNV and control of the disease relies on mosquito management and vaccination.

\subsubsection{Current vaccines}

Vaccination with inactivated or modified live vaccines has been an effective mechanism for the prevention of flavivirus infection in humans $[43,101]$ and domestic animals [82]. Protection against WNV viraemia, considered to be the most consistent indicator of infection, was accepted by the USDA as a means of assessing the efficacy of experimental vaccines against WNV. An inactivated and adjuvanted whole virus vaccine against WNV is licensed in the United States for use in horses. The manufacturer claims $94 \%$ protection against viraemia (based on preventable fraction calculation) 12 months after two initial doses of the vaccine. Protection was assessed by a parental challenge with WNV.

\subsubsection{Novel vaccination strategies for $W N V$}

Davis et al. [21] reported the evaluation of a DNA vaccine containing the preM/E genes of WNV against an experimental WNV mosquito-challenge in mice and horses, a method that approximates the natural type of exposure. A single dose of vaccine induced plaque reduction neutralisation antibody titres and protected all of the horses against WNV viraemia. The use of recombinant poxviruses is another potentially effective means of generating protective immunity against flavivirus infection $[45,49,50]$. We have developed a canarypox virus vector (vCP2017) expressing the $\mathrm{prM} / \mathrm{E}$ genes of a NY99 isolate of WNV
[62]. The protective capacity of vCP2017 was tested by challenging vaccinated horses via the bite of WNV infected mosquitoes. The vaccine induced neutralising antibodies to WNV and provided both an early onset and an established one year duration of immunity to horses. Most recently, this vaccine was approved by the USDA for use in horses.

\section{CONCLUSION}

Novel technologies offer unique opportunities for the improvement of existing vaccines or the development of vaccines against diseases for which licensed vaccines are currently not available. However, only a limited number of veterinary recombinant vaccines have been released to the market and only two such vaccines are currently available for the equine industry. Recombinant vaccines have been well accepted by the veterinary profession and owners, who immediately recognised the decisive advantages of these products compared to conventional vaccines. Major limitations for the development of recombinant vaccines are insufficient knowledge of the protective immunogens and their interaction with the equine immune system and (perceived) regulatory hurdles. It is now expected that rapid progress in the technology of antigen screening and understanding of the equine immune system will help the design of many new vaccines to prevent, control and possibly eradicate equine disease.

\section{ACKNOWLEDGEMENTS}

The authors wish to thank H. Hughes, K. Karaca, B. Nordgren and J. Castillo-Olivares for valuable advice and J. Daly, M. Murray and $\mathrm{H}$. Townsend for critical reading of the manuscript.

\section{REFERENCES}

[1] Allen G.P., Bryans J.T., Molecular epizootiology, pathogenesis and prophylaxis of equine 
herpesvirus-1 infections, Prog. Vet. Microbiol. Immunol. 2 (1986) 78-144.

[2] Allen G.P., Kydd J.H., Slater J.D., Smith K.C., Advances in understanding of the pathogenesis, epidemiology and immunological control of equine herpesvirus abortion, in: Wernery U., Wade J.F., Mumford J.A., Kaaden O.R. (Eds.), Equine Infectious diseases VIII, R\&W Publications Ltd, Newmarket, 1998, p. 129.

[3] Allen G.P., Yeragan M.R., Turtinen L.W., Bryans J.T., A new field strain of equine abortion virus (equine herpesvirus-1) among Kentucky horses, Am. J. Vet. Res. 46 (1985) 138140.

[4] Audonnet J.C., Mumford J.A., Jessett D.M., Pardo M.C., Taylor J., Tartaglia J., Minke J.M., Safety and efficacy of a canarypox-EHV recombinant in horses, in: Wernery U., Wade J.F., Mumford J.A., Kaaden O.R. (Eds.), Equine Infectious diseases VIII, R\&W Publications Ltd, Newmarket, 1998, pp. 418-419.

[5] Balasuriya U.B., Heidner H.W., Davis N.L., Wagner H.M., Hullinger P.J., Hedges J.F., Williams J.C., Johnston R.E., Wilson W.D, Liu I.K., MacLachlan N.J., Alphavirus replicon particles expressing the two major envelope proteins of equine arteritis virus induce high level protection against challenge with virulent virus in vaccinated horses, Vaccine 20 (2002) 1609-1617.

[6] Bennett A.M., Lescott T., Phillpotts R.J., Improved protection against Venezuelan equine encephalitis by genetic engineering of a recombinant vaccinia virus, Viral Immunol. 11 (1998) 109-117.

[7] Berge T.O., Banks I.S., Tigertt W.D., Attenuation of Venezuelan equine encephalomyelitis vaccine by in vitro cultivation in guinea-pig heart cells, Am. J. Hyg. 73 (1961) 209-218.

[8] Bowen R.A., Short W.A., Cropp C.B., Mathews J.H., Roehrig J.T., Kinney R.M., DeMartini J.C., Trent D.W., Protection of horses immunized with recombinant vaccinea-Venezuelan Equine encephalitis vaccine, Vaccine Res. 1 (1992) 111-121.

[9] Bryans J.T., Doll E.R., Wilson J.C., McCollum W.H., Immunisation for equine influenza, J. Am. Vet. Med. Assoc. 148 (1966) 413-417.

[10] Bunning M.L., Bowen R.A., Cropp C.B., Sullivan K.G., Davis B.S., Komar N., Godsey M.S., Baker D., Hettler D.L., Holmes D.A., Biggerstaff B.J., Mitchell C.J., Experimental infection of horses with West Nile virus, Emerg. Infect. Dis. 8 (2002) 380-386.

[11] Bürki F., Nowotny N., Oulehla J., Schmehlik O., Möstl K., Pallan C., Rossmanith E., Attempts to immunoprotect adult horses, spe- cifically pregnant mares, with commercial vaccines against clinical disease induced by equine herpesvirus-1, J. Vet. Med. 38 (1991) 432-440.

[12] Bürki F., Rossmanith W., Nowotny N., Pallan C., Möstl K., Lussy H., Viraemia and abortions are not prevented by two commercial Equine herpesvirus 1 vaccines after experimental challenge of horses, Vet. Q. 12 (1990) 80-86.

[13] Burrows R., Goodridge D., Equid herpesvirus 1 (EHV-1): some observations on the epizootiology of infection and on the innocuity testing of live virus vaccines, in: Proc. 24th Annu. Conf. Am. Ass. Equine Practitioners, St. Louis, 1978, pp. 17-29.

[14] Burrows R., Goodridge D., Denyer M.S., Trials of an inactivated equid herpes virus vaccine: challenge with a subtype 1 virus, Vet. Rec. 114 (1984) 369-374.

[15] Calisher C.H., Monath T.P., Mitchell C.J., Sabatinni M.S., Cropp C.B., Kerschner J., Hunt A.R., Lazuick J.S., Arbovirus investigations in Argentina, 1977-1980. III. Identification and characterization of viruses isolated including new subtypes of Western and Venezuelan equine encephalitis viruses and four new bunyaviruses (Las Maloyas, Resistencia, Barranqueras and Antequera), Am. J. Trop. Med. Hyg. 34 (1985) 956-965.

[16] Castillo-Olivares J., de Vries A.A., Raamsman M.J., Rottier P.J., Lakani K., Westcott D. Tearle J.P., Wood J.L., Mumford J.A., Hannant D., Davis-Poynter N.J., Evaluation of a prototype sub-unit vaccine against equine arteritis virus comprising the entire ectodomain of the virus envelope glycoprotein $\left(\mathrm{G}_{\mathrm{L}}\right)$ : induction of virus neutralising antibody and assessment of protection in ponies, J. Gen. Virol. 82 (2001) 2425-2435.

[17] Castillo-Olivares J., Wieringa R., Bakonyi T., de Vries A.A., Davis-Poynter N.J., Rottier P.J., Generation of a candidate live marker vaccine for equine arteritis virus by deletion of the major virus neutralization domain, $\mathrm{J}$. Virol. 77 (2003) 8470-8480.

[18] Chambers T.M., Holland R.E., Tudor L.R., Townsend H.G., Cook A., Bogdan J., Lunn D.P., Hussey S., Whitaker-Dowling P., Youngner J.S., Sebring R.W., Penner S.J., Stiegler G.L., A new modified live equine influenza virus vaccine: phenotypic stability, restricted spread and efficacy against heterologous virus challenge, Equine Vet. J. 33 (2001) 630-636.

[19] Chirnside E.D., Francis P.M., Mumford J.A. Expression cloning and antigenic analysis of the nucleocapsid protein of equine arteritis virus, Virus Res. 39 (1995) 277-288. 
[20] Cullinane A., Weld J., Osborne M., Nelly M., McBride C., Walsh C., Field studies on equine influenza vaccination regimes in thoroughbred foals and yearlings, Vet. J. 161 (2001) 174-185.

[21] Davis B.S., Chang G.J., Cropp B., Roehrig J.T., Martin D.A., Mitchell C.J., Bowen R.A., Bunning M.L., West Nile virus recombinant DNA vaccine protects mouse and horse from virus challenge and expresses in vitro a noninfectious recombinant antigen that can be used in enzyme-linked immunosorbent assays, J. Virol. 9 ( 2001 ) 4040-4047.

[22] Davis N.L., Willis L.V., Smith J.F., Johnston R.E., In vitro synthesis of infectious Venezuelan encephalitis virus RNA from a cDNA clone. Analysis of a viable deletion mutant, Virology 171 (1989) 189-204.

[23] Doll E.R., Immunization against viral rhinopneumonitis of horses with live virus propagated in hamsters, J. Biochem. 139 (1961) $1324-1330$

[24] Doll E.R., Bryans J.T., Immunization of young horses against viral rhinopneumonitis, Cornell Vet. 53 (1963) 24-41.

[25] Doll E.R., Bryans J.T., McCollum W.H., A procedure for evaluating the antigenicity of killed virus vaccines for equine rhinopneumonitis, Cornell Vet. 49 (1959) 212-220.

[26] Eddy G.A., Martin D.H., Reeves W.C., Johnston K.M., Field studies of an attenuated Venezuelan equine encephalomyelitis vaccine (strain TC-83), Infect. Immun. 5 (1972) 160-163.

[27] Ferguson J.A., Reeves W.C., Milby M.M., Hardy J.L., Study of homologous and heterologous antibody response in California horses vaccinated with attenuated Venezuelan equine encephalomyelitis vaccine (strain TC83), Am. J. Vet. Res. 39 (1978) 371-376.

[28] Fischer J., Barzu S., Andreoni C., Buisson N., Brun A., Audonnet J.C., DNA vaccination of neonate piglets in the face of maternal immunity induces humoral memory and protection against a virulent pseudorabies virus challenge, Vaccine 21 (2003) 1732-1741.

[29] Fischer L., Minke J., Dufay N., Baudu Ph., Audonnet J.C., Rabies DNA vaccine in the horse: strategies to improve serological responses, Vaccine 21 (2003) 4593-4596.

[30] Fitzpatrick D.R., Studdert M.J., Immunologic relationships between equine herpesvirus type 1 (equine abortion virus) and type 4 (equine rhinopneumonitis virus), Am. J. Vet. Res. 45 (1984) 1947-1952.

[31] Franck P., Round table on epidemic control, in: Venezuelan encephalitis (Scientific Publi- cation No. 243), Washington, Pan American Health Organisation, 1972, pp. 400-401.

[32] Franklin R.P., Kinde H., Jay M.T., Kramer L.D., Green E.G., Chiles R.E., Ostlund E., Husted S., Smith J., Parker M.D., Eastern equine encephalomyelitis virus infections in a horse from California, Emerg. Infect. Dis. 8 (2002) 283-288.

[33] Fukunaga Y., Wada R., Hirasawa K., Kamada M., Kunanomido T., Akiyama Y., Effect of the modified Bucyrus strain of equine arteritis virus experimentally inoculated into horses, Bull. Equine Res. Inst. 19 (1982) 97-101.

[34] Fukunaga Y., Wada R., Matsumura T., Sugiura $\mathrm{T}$., Imagawa H., Induction of immune response and protection from equine viral arteritis (EVA) by formalin inactivated-virus vaccine for EVA in horses, J. Vet. Med. B 37 (1990) 135-141.

[35] Fukunaga Y., Wada R., Kanemaru T., Imagawa H., Kamada M., Samejima T., Immune potency of lyophilised, killed vaccine for equine viral arteritis and its protection against abortion in pregnant mares, J. Equine Vet. Sci. 16 (1996) 217-221.

[36] Fukunaga Y., Wada R., Imagawa H., Kanemaru $\mathrm{T}$., Venereal infection of mares by equine arteritis virus and use of killed vaccine against the infection, J. Comp. Pathol. 117 (1997) 201-208.

[37] Glaser A.L., de Vries A.A., Raamsman M.J., Horzinek M.C., Rottier P.J., An infectious clone of equine arteritis virus: a tool for future fundamental studies and vaccine development, in: Wernery U., Wade J.F., Mumford J.A., Kaaden O.R. (Eds.), Equine Infectious diseases VIII, R\&W Publications Ltd, Newmarket, 1998, pp. 166-176.

[38] Hannant D., Mumford J.A., Cell mediated immune responses in ponies following infection with equine influenza virus (H3N8): the influence of induction culture conditions on the properties of cytotoxic effector cells, Vet. Immunol. Immunopathol. 21 (1989) 327337.

[39] Hannant D., Easeman R., Mumford J.A., Equine mucosal immune system: intranasal vaccination with inactivated influenza virus protects from infection, in: Wernery U., Wade J.F., Mumford J.A., Kaaden O.R. (Eds.), Equine Infectious diseases VIII, R\&W Publications Ltd, Newmarket, 1998, pp. 50-56.

[40] Heldens J.G., Hannant D., Cullinane A.A., Prendergast M.J., Mumford J.A., Nelly M., Kydd J.H., Weststrate M.W., van der Hoven R., Clinical and virological evaluation of the efficacy of an inactivated EHV1and EHV4 whole virus vaccine (Duvaxyn EHV1,4) 
Vaccination/challenge experiments in foals and pregnant mares, Vaccine 19 (2001) 97114.

[41] Heldens J.G., Kersten A.J., Weststrate M.W., van den Hoven R., Duration of immunity induced by an adjuvanted and inactivated equine influenza, tetanus and equine herpes 1 and 4 combination vaccine, Vet. Q. 23 (2001) 210-217.

[42] Hodgson L.A., Ludwig G.V., Smith J.F., Expression, processing and immunogenicity of structural proteins of Venezuelan encephalitis virus from recombinant baculovirus, Vaccine 17 (1999) 1151-1160.

[43] Hoke C.H., Nisalak A., Sangawhipa N., Jatanasen S., Laorakapongse T., Innis B.L., Kotchasenee S., Gingrich J.B., Latendresse J., Fukai K., Burke D.S., Protection against Japanese encephalitis by inactivated vaccines, $\mathrm{N}$. Engl. J. Med. 319 (1988) 608-614.

[44] Jessett D.M., Schrag D., Mumford J.A., Protection by an attenuated EHV-1 vaccine against challenge with a virulent EHV-1 AB4 isolate, in: Wernery U., Wade J.F., Mumford J.A., Kaaden O.R. (Eds.), Equine Infectious Diseases VIII, R\&W Publications Ltd, Newmarket, 1998, pp. 414-415.

[45] Kanesa-thasan N., Smucny J.J., Hoke C.H., Marks D.H., Konishi E., Kurane I., Tang D.B., Vaughn D.W., Mason P.W., Shope R.E., Safety and immunogenicity of NYCAC-JEV and ALVAC-JEV attenuated recombinant Japanese encephalitis virus - poxvirus vaccines in vaccinia-nonimmune and vacciniaimmune humans, Vaccine 19 (2001) 483491.

[46] Kinney R.M., Esposito J.J., Mathews J.H., Johnson B.J., Roehrig J.T., Barrett A.D., Trent D.W., Recombinant vaccinia virus/ Venezuelan equine encephalitis (VEE) virus protects mice from peripheral VEE virus challenge, J. Virol. 62 (1988) 4697-4702.

[47] Kinney R.M., Tsuchiya K.R., Sneider J.M., Trent D.W., Molecular evidence for the origin of the widespread Venezuelan encephalitis epizootic of 1969 to 1972 , J. Gen. Virol. 73 (1992) 3301-3305.

[48] Klein N., Duration of immunity, in: Mumford J.A., Daly J.M., Wade J.F. (Eds.), Proceedings of Fourth International Meeting of OIE and WHO Experts on Control of Equine Influenza, Miami, USA, R\&W Publications Ltd, Newmarket, 2003, pp. 36-37.

[49] Konishi E., Pincus S., Paoletti E., Laegreid W.W., Shope R.E., Mason P., A highly attenuated host range-restricted vaccinia virus strain, NYVAC, encoding the prM, E, and NS1 genes of Japanese encephalitis virus pre- vents JEV viremia in swine, Virology 190 (1992) 454-458.

[50] Konishi E., Kurane I., Mason P., Shope R.E., Ennis F.A., Pox virus-based Japanese encephalitis vaccine candidates induced JE virus-specific $\mathrm{CD} 8^{+}$cytotoxic lymphocytes in mice, Virology 227 (1997) 353-360.

[51] Liu I.K.M., Castleman W., Equine posterior paresis associated with equine herpesvirus 1 vaccine in California: a preliminary report, J. Equine Med. Surg. 1 (1977) 397-401.

[52] Luedke A.J., Barber T.L., Foster N.M., Batalla D., Mercado S., Effect of back passage of Venezuelan equine encephalomyelitis TC83 vaccine virus on clinical, virologic and immune responses in horses, J. Am. Vet. Med. Assoc. 161 (1972) 824-831.

[53] Lunn D.P., Soboll G., Schramm B.R., Quass J., McGregor M.W., Drape R.J., Macklin M.D., McCabe D.E., Swain W.F., Olsen C.W., Antibody responses to DNA vaccination of horses using the influenza virus hemagglutinin gene, Vaccine 17 (1999) 2245-2258.

[54] Matsumura T., Kondo T., Sugita S., Damiani A.M., O'Callaghan D.J., Imagawa H., An equine herpesvirus type 1 recombinant with a deletion in the gE gene and gI genes is avirulent in young horses, Virology 242 (1998) 68-79.

[55] Mayr A., Pette J., Petzoldt K., Wagener K., Untersuchungen zur Entwicklung eines Lebendimstofstoffes gegen die Rhinopneumonitis (stutenabort) der Pferde, Zentralbl. Veterinaermed. B 15 (1968) 406-418.

[56] McCollum W.H., Development of a modified virus strain and vaccine for equine viral arteritis, J. Am. Vet. Med. Assoc. 155 (1969) 318322 .

[57] McGuire T.C., Tumas D.B., Hines M.T., Leib S.R., Brassfield A.L., O’Rourke K.I., Perryman L.E., Major histocompatibility complexrestricted $\mathrm{CD}^{+}$cytotoxic $\mathrm{T}$ lymphocytes from horses with equine infectious anemia virus recognize Env and Gag/PR proteins, J. Virol. 68 (1994) 1459-1467.

[58] McKinnon A.O., Colbern G.T., Collins J.K., Bowen R.A., Voss J.L., Umphenour J.W., Vaccination of stallions with a modified live equine viral arteritis virus, J. Equine Vet. Sci. 6 (1986) 66-69.

[59] Mellencamp M., Schultze A., Development of an inactivated equine influenza vaccine to meet global requirements, in: Proceedings Quality Control of Equine Influenza Vaccines, Budapest, 2001, pp. 79-81. 
[60] Minke J.M., Flore P.H., Vaarten J., Vandehoek J., Weststrate M., An inactivated EHV-1 and EHV-4 containing vaccine reduces clinical signs in horses infected experimentally with EHV-1 or EHV-4 six months after a single vaccination, in: Wernery U., Wade J.F., Mumford J.A., Kaaden O.R. (Eds.), Equine Infectious diseases VIII, R\&W Publications Ltd, Newmarket, 1998, pp. 564-565.

[61] Minke J.M., Audonnet J.C., Jessett D.M., Fischer L., Guigal P.M., Coupier H., Pardo M.C., Taylor J., Tartaglia J., Mumford J.A., Canarypox as vector for influenza and EHV-1 genes: challenges and rewards, in: 2nd International Veterinary Vaccines and Diagnostics Conference, Oxford, 2000, p.36.

[62] Minke J.M., Siger L., Karaca K., Austgen L., Gordy P., Bowen R., Renshaw R.W., Loosmoore S., Audonnet J.C., Nordgren B., Recombinant canarypox virus carrying the preM/E genes of West Nile virus protects horses against a West Nile virus-mosquito challenge, Arch. Virol. Suppl. 18 (2004) 221-230.

[63] Morley P.S., Townsend H.G., Bogdan J.R., Haines D.M., Risk factors for disease associated with influenza virus infections during three epidemics in horses, J. Am. Vet. Med. Assoc. 216 (2000) 545-550.

[64] Mumford J.A., Control of influenza from an international perspective, in: Wernery U., Wade J.F., Mumford J.A., Kaaden O.R. (Eds.), Equine Infectious diseases VIII, R\&W Publications Ltd, Newmarket, 1998, pp. 11-24.

[65] Mumford J.A., Wood J., Establishing an acceptable threshold for equine influenza vaccines, Dev. Biol. Stand. 79 (1992) 137-146.

[66] Mumford J.A., Hannant D., Jessett D.M., O'Neill T., Evaluation of protective efficacy of equid herpesvirus type 1 ISCOM vaccine for the abortigenic form of disease, J. Reprod. Fertil. 44 Suppl. (1991) 730-731.

[67] Mumford J.A., Jessett D.M., Rollinson E.A., Hannant D., Draper M.E., Duration of protective efficacy in equine influenza immunostimulating complex/tetanus vaccines, Vet. Rec. 134 (1994) 158-162.

[68] Mumford J.A., Wilson H., Hannant D., Jessett D.M., Antigenicity and immunogenicity of equine influenza vaccines containing a Carbomer adjuvant, Epidemiol. Infect. 112 (1994) 421-437.

[69] Nelson K.M., Schram B.R., McGregor M.W. Sheoran A.S., Olsen C.W., Lunn D.P., Local and systemic isotype-specific antibody responses to equine influenza virus infection versus conventional vaccination, Vaccine 16 (1998) 1306-1313.
[70] Neubauer A., Meindl A., Osterrieder N., Mutations in the US2 and glycoprotein B genes of the equine herpesvirus 1 vaccine strain $\mathrm{RacH}$ have no effects on its attenuation, Berl. Muench. Tieraerztl. Wochenschr. 112 (1999) 351-354.

[71] Nugent J., Sinclair R., de Vries A.A., Eberhardt R.Y., Castillo-Olivares J., Davis-Poynter N., Rottier P.J., Mumford J.A., Development and evaluation of ELISA procedures to detect antibodies against the major envelope protein (GL) of equine arteritis virus, J. Virol. Methods 90 (2000) 167-183.

[72] Oberste M.S., Fraire M., Navarro R., Zepeda C., Zarate M.L., Ludwig G.V., Kondig J.F., Weaver S.C., Smith J.F., Rico-Hesse R., Association of Venezuelan equine encephalitis virus subtype IE with two equine epizootics in Mexico, Am. J. Trop. Med. Hyg. 59 (1998) 100-107.

[73] Paessler S., Fayzulin R.Z., Anishchenko M., Greene I.P., Weaver S.C., Frolov I., Recombinant Sindbis/VEE virus is highly attenuated and immunogenic, J. Virol. 77 (2003) 92789286.

[74] Palfi V., Christensen L.S., Analyses of restriction fragment (RFPs) and pathogenicity in baby mice of equine herpesvirus 1 and 4 (EHV-1 and EHV-4) strains circulating in Danish horses, Vet. Microbiol. 47 (1995) 199-204.

[75] Pardo M.C., Bauman J.E., Mackowiak M., Protection of dogs against canine distemper by vaccination with a canarypox virus recombinant expressing canine distemper virus fusion and hemagglutinin glycoproteins, Am. J. Vet. Res. 58 (1997) 833-836.

[76] Patel J.R., Földi J., Bateman H., Williams J., Didlick S., Stark R., Equid herpesvirus (EHV1) live vaccine strain C147: efficacy against respiratory disease following EHV types 1 and 4 challenges, Vet. Microbiol. 92 (2003) $1-17$.

[77] Pittman P.R., Makuch R.S., Mangiafico J.A., Cannon T.L., Gibbs P.H., Peters C.J., Longterm duration of detectable neutralizing antibodies after administration of live-attenuated VEE vaccine and following booster vaccination with inactivated VEE vaccine, Vaccine 14 (1996) 337-343.

[78] Plotkin S.A., Cadoz M., Meignier B., Meric C., Leroy O., Excler J.L., Tartaglia J., Paoleti E., Gonczol E., Chappuis G., The safety and use of canarypox vectored vaccines, Dev. Biol. Stand. 84 (1995) 165-170.

[79] Poulet H., Brunet S., Boularand C., Guiot A.L., Leroy V., Tartaglia J., Minke J., Audonnet J.C., Desmettre P., Efficacy of a canarypox virus-vectored vaccine against feline leukaemia, Vet. Rec. 153 (2003) 141-145. 
[80] Powell D.G., Short review: Epidemiology and control of equine viral disease, in: Studdert M.J. (Ed.), Virus infections of Vertebrates 6, Elsevier, Amsterdam, 1996, pp. $327-339$.

[81] Pratt W.D., Davis N.L., Johnston R.E., Smith J.F., Genetically engineered, live attenuated vaccines for Venezuelan equine encephalitis: testing in animal models, Vaccine 21 (2003) 3854-3862.

[82] Research Committee for prevention of stillbirth in sows due to Japanese encephalitis, Bull. Natl. Inst. Anim. Health 57 (1968) 1-8.

[83] Robinson H.L., DNA vaccines: basic mechanism and immune responses, Int. J. Mol. Med. 4 (1999) 549-555.

[84] Schoepp R.J., Smith J.F., Parker M.D., Recombinant chimeric Western and Eastern Encephalitis viruses as potential vaccine candidates, Virology 302 (2002) 299-309.

[85] Siegrist C.A., Saddallah F., Tougne C., Martinez X., Kovarik J., Lamber P.H., Induction of neonatal TH1 and CTL responses by live viral vaccines: a role for replication patterns within antigen presenting cells, Vaccine 16 (1998) 1473-1478.

[86] Slater J.D., Gibson J.S., Field H.J., Pathogenicity of a thymidine kinase-deficient mutant of equine herpesvirus 1 in mice and specific pathogen-free foals, J. Gen. Virol. 74 (1993) 819-828.

[87] Soboll G., Whalley J.M., Koen M.T., Allen G.P., Fraser D.G., Macklin M.D., Swain W.F., Lunn D.P., Identification of equine herpesvirus-1 antigens recognized by cytotoxic T lymphocytes, J. Gen. Virol. 84 (2003) 2625-2634.

[88] Taylor J., Trimarchi C., Weinberg R., Languet B., Guillemin F., Desmettre P., Paoletti E., Efficacy studies on a canarypox-rabies recombinant virus, Vaccine 9 (1991) 190193.

[89] Tewari D., Gibson J.S., Slater J.D., O’Neill T., Hannant D., Allen G.P., Field H.J., Modulation of the serological response of specific pathogen-free (EHV-free) foals to EHV-1 by previous infection to EHV-4 or a TK-deletion mutant of EHV-1, Arch. Virol. 132 (1993) 101-120.

[90] Thomson G.R., Mumford J.A., Smith I.M., Experimental immunization against respiratory disease due to equine herpesvirus 1 infection (rhinopneumonitis) using formalininactivated virus with various adjuvants, Vet. Microbiol. 4 (1979) 209-222.
[91] Timoney P.J., McCollum W.H., Equine viral arteritis: epidemiology and control, J. Equine Vet. Sci. 8 (1988) 54-59.

[92] Townsend H.G., Penner S.J., Watts T.C., Cook A., Bogdan J., Haines D.M., Griffin S., Chambers T., Holland R.E., Whitaker-Dowling P., Younger J.S., Sebring R.W., Efficacy of a cold-adapted, intranasal, equine influenza vaccine: challenge trials, Equine Vet. J. 33 (2001) 637-643.

[93] Van Maanen C., Equine herpes virus 1 and 4 infections: an update, Vet. Q. 24 (2002) $57-78$.

[94] Van Maanen C., Bruin G., de Boer-Luytze E. Smolders G., De Boer G.F., Interference of maternal antibodies with the immune response of foals after vaccination against equine influenza, Vet. Q. 14 (1992) 13-17.

[95] Van Oirschot J.T., Present and future of veterinary viral vaccinology: a review, Vet. Q. 23 (2001) 100-108.

[96] Van Oirschot J., Bruin G., De Boer-Luytze E., Smolders G., Maternal antibodies against equine influenza virus in foals and their interference with vaccination, J. Vet. Med. 38 (1991) 391-396.

[97] Walton T.E., Brantigam F.E., Ferrer J.A., Johnson K.M., Epizootic Venezuelan equine encephalomyelitis in Central America. Disease pattern and vaccine evaluation in Nicaragua, 1969-1970, Am. J. Epidemiol. 95 (1972) 247-254

[98] Walton T.E., Alvarez O., Buckwalter R.M., Johnson K.M., Experimental infection of horses with an attenuated Venezuelan equine encephalitis vaccine (strain TC-83), J. Infect. Dis. 128 (1973) 271-282.

[99] Webster R.G., Are equine 1 influenza viruses still present in horses ? Equine Vet. J. 25 (1993) 537-539.

[100] Whalen J.W., Hall V.L., Srinivasappa J., Ross C., Eichmeyer M., Chu S., An inactivated vaccine prevents persistent equine arteritis virus infection in stallions, in: Wernery U., Wade J.F., Mumford J.A., Kaaden O.R. (Eds.), Equine Infectious diseases VIII, R\&W Publications Ltd, Newmarket, 1998, p. 595.

[101] Xin Y.Y., Ming Z.G., Peng G.Y., Jian A., Min L.H., Safety of a live-attenuated Japanese encephalitis virus vaccine (SA14-14-2) for children, Am. J. Trop. Med. Hyg. 39 (1988) 214-217.

[102] Yates P., Mumford J.A., Equine influenza vaccine efficacy: the significance of antigenic variation, Vet. Microbiol. 74 (2000) 173-177. 